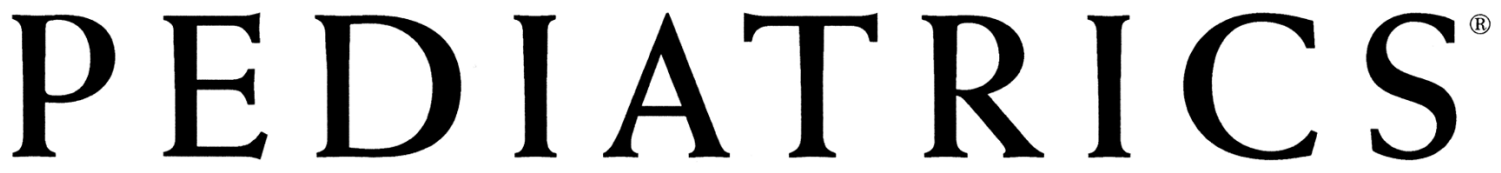

OFFICIAL JOURNAL OF THE AMERICAN ACADEMY OF PEDIATRICS

\title{
Persistent Sterile Leukocyturia Is Associated With Impaired Renal Function in Human Immunodeficiency Virus Type 1-Infected Children Treated With Indinavir
}

Annemarie M. C. van Rossum, Jeanne P. Dieleman, Pieter L. A. Fraaij, Karlien Cransberg, Nico G. Hartwig, David M. Burger, Inge C. Gyssens and Ronald de Groot Pediatrics 2002;110;19-

DOI: $10.1542 /$ peds.110.2.e19

\section{This information is current as of November 15, 2006}

The online version of this article, along with updated information and services, is located on the World Wide Web at:

http://www.pediatrics.org/cgi/content/full/110/2/e19

PEDIATRICS is the official journal of the American Academy of Pediatrics. A monthly publication, it has been published continuously since 1948. PEDIATRICS is owned, published, and trademarked by the American Academy of Pediatrics, 141 Northwest Point Boulevard, Elk Grove Village, Illinois, 60007. Copyright $\odot 2002$ by the American Academy of Pediatrics. All rights reserved. Print ISSN: 0031-4005. Online ISSN: 1098-4275.

\section{American Academy of Pediatrics}




\title{
Persistent Sterile Leukocyturia Is Associated With Impaired Renal Function in Human Immunodeficiency Virus Type 1-Infected Children Treated With Indinavir
}

\author{
Annemarie M. C. van Rossum, MD, PhD; Jeanne P. Dieleman, PhD ; Pieter L. A. Fraaij, MD*; \\ Karlien Cransberg, MD*; Nico G. Hartwig, MD, PhD*; David M. Burger, PharmD, PhD§; \\ Inge C. Gyssens, MD, PhD‡;\|; and Ronald de Groot, MD, PhD*
}

\begin{abstract}
Background. Prolonged administration of indinavir is associated with the occurrence of a variety of renal complications in adults. These well-documented side effects have restricted the use of this potent protease inhibitor in children.

Design. A prospective study to monitor indinavir-related nephrotoxicity in a cohort of 30 human immunodeficiency virus type 1-infected children treated with indinavir.

Methods. Urinary $\mathrm{pH}$, albumin, creatinine, the presence of erythrocytes, leukocytes, bacteria and crystals, and culture were analyzed every 3 months for 96 weeks. Serum creatinine levels were routinely determined at the same time points. Steady-state pharmacokinetics of indinavir were done at week 4 after the initiation of indinavir.
\end{abstract}

Results. The cumulative incidence of persistent sterile leukocyturia $(\geq 75$ cells $/ \mu \mathrm{L}$ in at least 2 consecutive visits) after 96 weeks was 53\%. Persistent sterile leukocyturia was frequently associated with a mild increase in the urine albumin/creatinine ratio and by microscopic hematuria. The cumulative incidence of serum creatinine levels $>50 \%$ above normal was $33 \%$ after 96 weeks. Children with persistent sterile leukocyturia more frequently had serum creatinine levels of $50 \%$ above normal than those children without persistent sterile leukocyturia. In children younger than $\mathbf{5 . 6}$ years, persistent sterile leukocyturia was significantly more frequent than in older children. A higher cumulative incidence of persistent leukocyturia was found in children with an area under the curve $>19 \mathrm{mg} / \mathrm{L}^{*} \mathrm{~h}$ or a peak serum level of indinavir $>12 \mathrm{mg} / \mathrm{L}$. In 4 children, indinavir was discontinued because of nephrotoxicity. Subsequently, the serum creatinine levels decreased, the urine albumin/creatinine ratios returned to zero, and the leukocyturia disappeared within 3 months.

Conclusions. Children treated with indinavir have a high cumulative incidence of persistent sterile leukocyturia. Children with persistent sterile leukocyturia more

\footnotetext{
From the *Department of Pediatrics, Sophia Children's Hospital/Erasmus University Medical Centre Rotterdam, Rotterdam, the Netherlands; $\ddagger$ Department of Internal Medicine, Erasmus University Medical Centre Rotterdam, Rotterdam, the Netherlands; §Department of Clinical Pharmacy, University Medical Centre Nijmegen, Nijmegen, the Netherlands; and \|Department of Medical Microbiology and Infectious Diseases, Erasmus University Medical Centre Rotterdam, Rotterdam, the Netherlands.

Received for publication Nov 2, 2001; accepted Apr 8, 2002.

Address correspondence to Ronald de Groot, MD, PhD, Sophia Children's Hospital, Dr. Molewaterplein 60, 3015 GJ Rotterdam, the Netherlands. E-mail: rdegroot@alkg.azr.nl

PEDIATRICS (ISSN 0031 4005). Copyright $\odot 2002$ by the American Academy of Pediatrics.
}

frequently had an increase in serum creatinine levels of $>50 \%$ above normal. Younger children have an additional risk for renal complications. The impairment of the renal function in these children occurred in the absence of clinical symptoms of nephrolithiasis. Indinavirassociated nephrotoxicity must be monitored closely, especially in children with risk factors such as persistent sterile leukocyturia, age $<5.6$ years, an area under the curve of indinavir $>19 \mathrm{mg} / \mathrm{L}^{*} \mathrm{~h}$, and a $\mathrm{C}_{\max }>12 \mathrm{mg} / \mathrm{L}$. Pediatrics 2002;110(2). URL: http://www.pediatrics.org/ cgi/content/full/110/2/e19; human immunodeficiency virus, children, indinavir, nephrotoxicity.

ABBREVIATIONS. HIV, human immunodeficiency virus; AUC, area under plasma-concentration curve; $\mathrm{IQR}$, interquartile range.

$\mathrm{I}$ ndinavir is a potent human immunodeficiency virus (HIV)-protease inhibitor that has been used successfully in adults in combination with nucleoside reverse transcriptase inhibitors to suppress infections by HIV-1. Discontinuation of the antiretroviral therapy rapidly results in virologic rebound, decreased immune function, and the redevelopment of acquired immune deficiency syndrome-defining illness. Thus, antiretroviral drugs such as indinavir need to be continued for many years. This necessitates a careful surveillance for long-term toxicity of the medication.

The experience with the administration of indinavir to HIV-1-infected children has been limited because of the absence of a pediatric formulation and the well-documented side-effects of the drug on the upper and lower urinary tract in adults. Indinavir is metabolized by the liver, but $\sim 20 \%$ of a single oral dose is excreted unchanged in the urine. ${ }^{1} \mathrm{pH}$-dependent crystallization of indinavir in renal tubuli may cause renal symptoms such as kidney stones, flank pain (even without evident stone formation), interstitial nephritis, elevation of the serum creatinine, dysuria, and asymptomatic urine abnormalities such as hematuria, leukocyturia, and crystalluria. Indinavir crystals may illicit an inflammatory response in the tubules, leading to sterile leukocyturia and renal insufficiency. ${ }^{2-7}$ To minimize renal side effects of indinavir, an increased fluid intake is advised. ${ }^{8}$

The incidence of indinavir-associated nephrolithiasis in adults varies from $4 \%$ to $43 \% .^{2,9}$ Renal complications (including nephrolithiasis) from indinavir 
are found in $0 \%$ to $80 \%{ }^{10-15}$ and nephrolithiasis in $0 \%$ to $20 \%{ }^{10,12-15}$ of children who have been treated with this drug.

Renal and urologic symptoms of indinavir crystals have been correlated with the serum levels of indinavir. ${ }^{16}$ In children, sufficiently high area under the plasma-concentration curves (AUCs) for indinavir are required to achieve trough levels ${ }^{13,17}$ associated with an optimal virologic response. ${ }^{18-20}$ The risk of nephrotoxicity in children might therefore be higher than in adults.

In contrast to symptomatic nephrolithiasis, other renal complications such as leukocyturia, microscopic hematuria, and crystalluria usually do not lead to a decision to discontinue indinavir, although an association between recurrent severe leukocyturia and renal damage by indinavir-induced crystalluria has been reported in adults. 6,21

Currently, it is unknown whether and when these asymptomatic signs of renal damage lead to renal complications and long-term renal damage. This prospective study was performed to monitor renal and urinary complications in a cohort of 30 HIV-1-infected children treated with indinavir. We hypothesized that indinavir-related nephrotoxicity might occur more frequently in children than in adults because of the higher risk for cellular damage to the still developing renal system.

\section{METHODS}

In 1997, a prospective, open, uncontrolled, multicenter study was initiated to evaluate the clinical, immunologic, and virologic response to combination therapy consisting of indinavir, zidovudine, and lamivudine in HIV-1-infected children. ${ }^{15}$ Children $>3$ months old and 1 of the following 2 items: a decreased CD $4^{+}$ T-cell count ( $<1$ year: $<1750 / \mathrm{mm}^{3}, 1$ to 2 years: $<1000 / \mathrm{mm}^{3}, 3$ to 6 years: $<750 / \mathrm{mm}^{3},>6$ years: $<500 / \mathrm{mm}^{3}$ ) or a HIV-1 RNA load $>5000$ copies $/ \mathrm{mL}$ were included. The follow-up period was 96 weeks after the initiation of indinavir. Two years after the initiation of this multicenter study, a separate study was started in 1 of the participating centers to analyze additional urinalysis parameters with a follow-up period of 96 weeks.

The Ethics Committee of the University Hospital Rotterdam approved the study. Patients and their caretakers provided written informed consent.

\section{Laboratory Parameters}

The routinely analyzed laboratory parameters of the children included dipstick analysis (Rapignost total screen L, Behring Diagnostics Inc, Westwood, MA) for urinary $\mathrm{pH}$ (at urine $\mathrm{pH}$ values below 5 solubility of indinavir increases ${ }^{22}$ ), erythrocytes, leukocytes, and bacteria at baseline (before the use of indinavir) and every 3 months thereafter. Routine biochemistry tests included serum creatinine. Steady-state pharmacokinetics of indinavir (400 $\mathrm{mg} / \mathrm{m}^{2}$ every 8 hours) were determined at week 4 after the initiation of indinavir. This procedure was repeated when a dosage adjustment of indinavir was necessary to normalize the area under AUC concentration to adult values $\left(20 \mathrm{mg} / \mathrm{L}^{*} \mathrm{~h}\right.$; range: $10-30$ $\left.\mathrm{mg} / \mathrm{L}^{*} \mathrm{~h}\right) \cdot{ }^{17}$

Demographic parameters, indinavir start date and stop date, indinavir dosing regimens, urinary tract symptoms, concomitant treatment, HIV-1 RNA, and CD4 ${ }^{+}$T-cell counts were recorded on structured data collection forms. Nephrolithiasis-related symptoms included renal colic, flank pain, the passing of a stone, and gross hematuria.

Additional laboratory tests were performed in children included in 1 center, from March 1999 onwards. Urinary pH was measured by means of calibrated electrode technique. Urine albumin and creatinine were measured to calculate the albumin to creatinine ratio as an indicator of renal damage. Urine light microscopy for presence of indinavir crystals under a polarized filter was performed and urine cultures were performed in patients with a positive dipstick test or microscopy for bacteria.

Sterile leukocyturia is considered to be caused by damage of renal tubuli. Therefore, we considered this the principal endpoint this study. Leukocyturia was defined by the presence of a dipstick test with $>75$ cells $/ \mu$ L. Persistent sterile leukocyturia was present when leukocyturia with negative urine cultures was found at at least 2 consecutive visits, after the start of indinavir. In children with $>150$ leukocytes $/ \mu \mathrm{L}$ at at least 2 visits and a negative urine culture a renal ultrasound was performed.

\section{Analysis}

Cumulative incidences of persistent leukocyturia and serum creatinine $>50 \%$ above age- and sex-specific normal values ${ }^{23}$ were calculated with Kaplan-Meier analysis. The influences of pharmacokinetic factors were determined with the log rank test. The relation between the occurrence of persistent leukocyturia and an increased creatinine and between persistent leukocyturia and nephrolithiasis-related symptoms were analyzed using the Fisher exact test. To describe urine abnormalities associated with leukocyturia, we performed a cross-sectional analysis 12 weeks after the start of the measurement of the additional urinalysis.

\section{RESULTS}

Thirty HIV-1-infected children were enrolled between April 1997 and April 2000. Fifteen children were available for additional analyses between March 1999 and March 2001. The other 15 children were not available for additional analyses for various reasons: enrollment in a center different from that where the additional analyses were performed $(n=$ $8)$, discontinuation of indinavir $(n=6 ; 5$ children because of virologic failure and 1 because of nephrotoxicity), and age $>18$ years $(n=1)$. Baseline characteristics of the children are presented in Table 1.

A good clinical, immunologic, and virologic response was observed in all children who were treated with indinavir. Most of the children needed $600 \mathrm{mg} / \mathrm{m}^{2}$ of indinavir every 8 hours to obtain an AUC of indinavir between 10 and $30 \mathrm{mg} / \mathrm{L}^{*} \mathrm{~h}$. The median interquartile range (IQR) AUC was 19 (1428) $\mathrm{mg} / \mathrm{L}^{*} \mathrm{~h}$ with a median (IQR) peak level of 9 $(6-12) \mathrm{mg} / \mathrm{L}$. Baseline and follow-up serum creatinine and urinalysis data were available from 30 children in whom indinavir was initiated.

\section{Cumulative Incidence of Persistent Sterile Leukocyturia ( $\geq 2$ Times $\geq 75$ Cells $/ \mu \mathrm{L}$ )}

Eleven $(37 \%)$ of 30 children developed persistent sterile leukocyturia ( 2 times or more $\geq 75$ leukocytes $/ \mu \mathrm{L}$ ). The cumulative incidence after 96 weeks was $53 \%$ with a mean time to leukocyturia of 74 weeks (95\% confidence interval: 61-87 weeks) of combination therapy containing indinavir (Fig 1A).

The influence of age and sex on the cumulative incidence of persistent sterile leukocyturia was determined. Children were divided into 2 groups: younger and older than the median age of 5.6 years. Figure 1B shows that children younger than 5.6 years had a significantly higher cumulative incidence of persistent sterile leukocyturia than children older than 5.6 years $(P=.05)$. Sex did not influence the incidence of leukocyturia. 
TABLE 1. Patient Characteristics

\begin{tabular}{llc}
\hline \multicolumn{1}{c}{ Characteristic } & \\
\hline Age $(\mathrm{y})$ & Median (range) & $5.6(2.4-9.9)$ \\
Male & $N(\%)$ & $15(50)$ \\
Body mass index $\left(\mathrm{kg} / \mathrm{m}^{2}\right)$ & Median (IQR) & $16(14-17)$ \\
HIV-1 RNA (copies $/ \mathrm{mL})$ & Median (IQR) & $12700(18400-661000)$ \\
CD 4 cells (cells $/ \mu \mathrm{L})$ & Median (IQR) & $610(230-880)$ \\
Indinavir regimen & $N(\%)$ & $8(27)$ \\
$400 \mathrm{mg} / \mathrm{m}^{2}$ tid & $N(\%)$ & $11(37)$ \\
$500 \mathrm{mg} / \mathrm{m}^{2}$ tid & $N(\%)$ & $7(23)$ \\
$600 \mathrm{mg} / \mathrm{m}^{2}$ tid & $N(\%)$ & $4(13)$ \\
$\geq 700 \mathrm{mg} / \mathrm{m}^{2}$ tid & $N(\%)$ & $24(19-38)$ \\
$500 / 100 \mathrm{mg}^{2} \mathrm{~m}^{2}$ bid & & \\
Serum creatinine $(\mu \mathrm{mol} / \mathrm{L})$ & Median (IQR) & $0(0)$ \\
Urine & $N(\%)$ & $0(0)$ \\
Leukocytes $>75$ cells $/ \mu \mathrm{L}$ & $N(\%)$ & \\
Erythrocytes $>60 \mathrm{cells} / \mu \mathrm{L}$ & & \\
\hline
\end{tabular}

* Indinavir/ritonavir.

Cumulative Incidence of a Change of Serum Creatinine $>\mathbf{5 0} \%$ Above Age- and Sex-Specific Normal Values

Six $(20 \%)$ of 30 children had a change of serum creatinine $>50 \%$ above age- and sex-specific normal values. The cumulative incidence after 96 weeks was $33 \%$ with a mean time to creatinine increase of 90 weeks (95\% confidence interval: 82-98 weeks) of combination therapy containing indinavir (Fig 1C).

\section{Relation Between Persistent Sterile Leukocyturia and an Increase of Serum Creatinine}

One $(5 \%)$ of the 19 children without persistent sterile leukocyturia had a change in serum creatinine $>50 \%$ above age- and sex-specific normal values, whereas $5(45 \%)$ of 11 children with persistent sterile leukocyturia had a change in serum creatinine $>50 \%$ above age- and sex-specific normal values $(P=.02)$. The median (IQR) time to a creatinine increase among patients with leukocyturia was $24(0-48)$ weeks.

\section{Relation Between Persistent Sterile Leukocyturia and Pharmacokinetic Parameters}

Children with an $\mathrm{AUC}_{0-8}$ of indinavir higher than the median AUC of $19 \mathrm{mg} / \mathrm{L}^{*} \mathrm{~h}$ had a significantly higher cumulative incidence of persistent sterile leukocyturia compared with those with an AUC $\leq 19$ $\mathrm{mg} / \mathrm{L}^{*} \mathrm{~h}(P=.05)$. After 96 weeks $8(67 \%)$ of the 12 children with an AUC $>19 \mathrm{mg} / \mathrm{L}^{*} \mathrm{~h}$ had persistent sterile leukocyturia, in contrast with $2(13 \%)$ of 16 of the children with an AUC $<19 \mathrm{mg} / \mathrm{L}^{*} \mathrm{~h}$. The cumulative incidences were $79 \%$ and $19 \%$, respectively, after 96 weeks (Fig 1D). Having a maximum concentration $\left(C_{\max }\right)$ of indinavir of $12(\mathrm{mg} / \mathrm{L})$ was significantly $(P=.02)$ associated with the presence of persistent sterile leukocyturia. (Fig 1F). Five (24\%) of the 21 children with a $\mathrm{C}_{\max }<12 \mathrm{mg} / \mathrm{L}$ had persistent sterile leukocyturia, whereas in $5(71 \%)$ of 7 children with a $C_{\max } \geq 12 \mathrm{mg} / \mathrm{L}$, this abnormality was observed. No relation was found between $C_{\min }$ and the presence of persistent sterile leukocyturia, between age and AUC of indinavir, and between age and $\mathrm{C}_{\max }$.

\section{Relation Between Persistent Sterile Leukocyturia and Nephrolithiasis-Related Symptoms}

Four $(19 \%)$ of the 21 children without persistent sterile leukocyturia presented with urologic symptoms, whereas $7(78 \%)$ of 9 children with persistent sterile leukocyturia had symptoms during the follow-up time $(P=.003)$.

\section{Hematuria}

Persistent hematuria ( $\geq 2 \times \geq 60$ cells $/ \mu \mathrm{L}$ ) was not detected in any child.

In addition to the standard analyses performed in the 30 children, urine creatinine, urine albumin, quantitative $\mathrm{pH}$ measurements, and crystalluria were analyzed in 15 children. At the time of the start of the additional analyses, these children were using indinavir for a median of 75 weeks (IQR: 8-77 weeks).

A cross-sectional analysis at week 12 after the start of the initiation of additional analysis showed that in these children (median time on indinavir [IQR]: 87 [20-89] weeks) $33 \%$ of the patients had a change of serum creatinine $>50 \%$ above age- and sex-specific normal values. In 4 of these 5 patients, an albumin/ creatinine ratio $>3.5 \mathrm{~g} / \mathrm{mmol}$ was observed. In 2 of these patients, indinavir was discontinued because of nephrolithiasis on renal ultrasound.

Forty-three percent of the patients had leukocyturia, $21 \%$ had microscopic hematuria, 54\% had crystalluria, and $29 \%$ had an albumin/creatinine ratio $\geq 3.5 \mathrm{~g} / \mathrm{mmol}$. Urine cultures were all negative for bacteria.

In Fig 2, urine abnormalities associated with leukocyturia at week 12 are presented. An increase of serum creatinine levels of $>50 \%$ above age- and sexspecific normal values, an albumin/creatinine ratio $\geq 3.5 \mathrm{~g} / \mathrm{mmol}$, and hematuria were observed more frequently in children with leukocyturia. The median (IQR) albumin/creatinine ratio of children with and without persistent leukocyturia was $0.7(0.6-2.5)$ and 2.8 (1.2-10.6), respectively. In contrast, indinavir crystalluria was not detected more frequently in children with leukocyturia. The presence of symptoms, urinary $\mathrm{pH}>5$, and the presence of crystalluria were not associated with persistent sterile leukocyturia. 
A

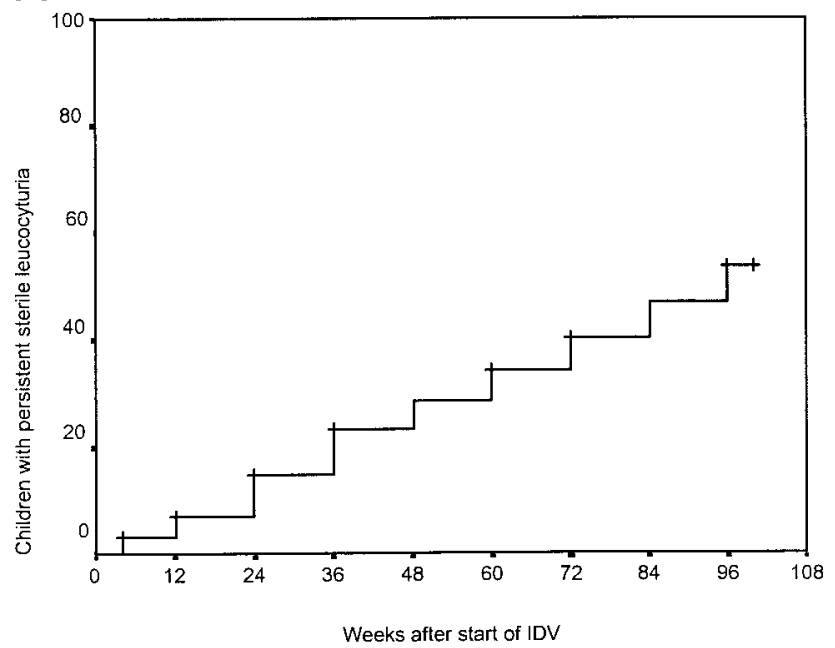

C

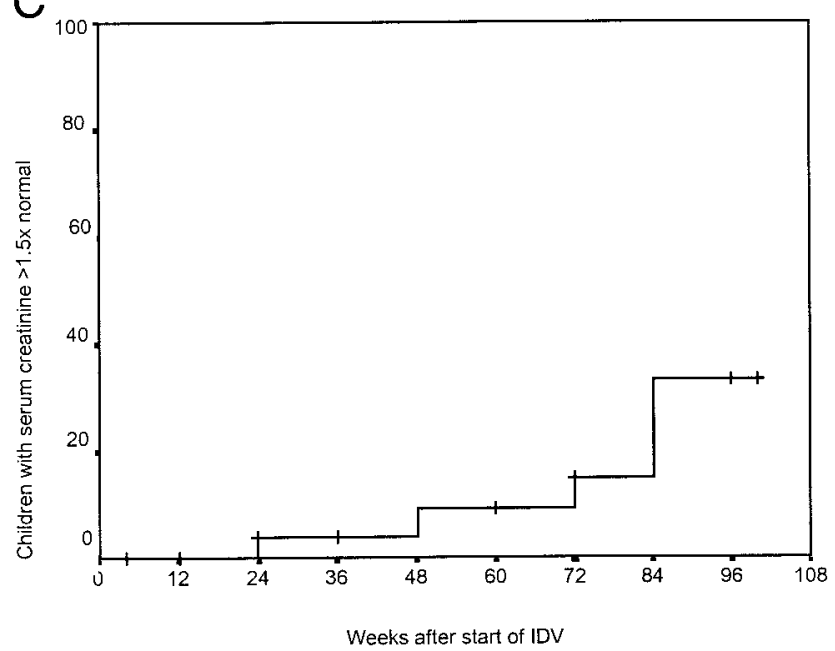

$\mathrm{E}$

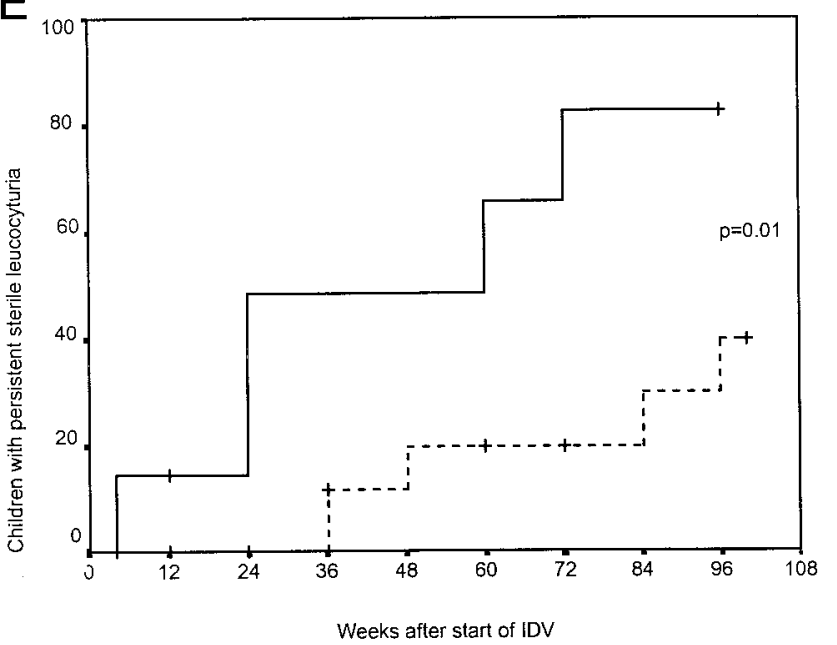

$\mathrm{B}$

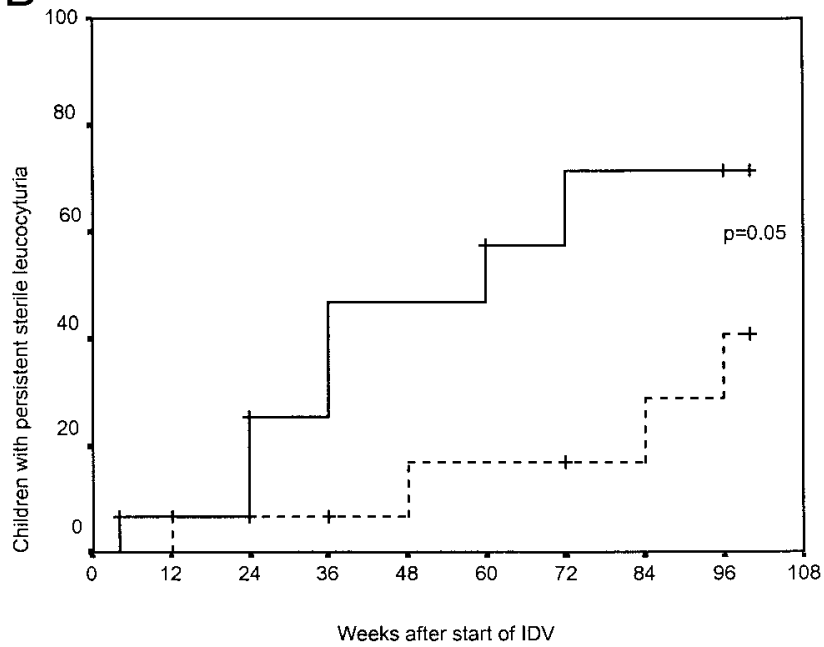

$\mathrm{D}$

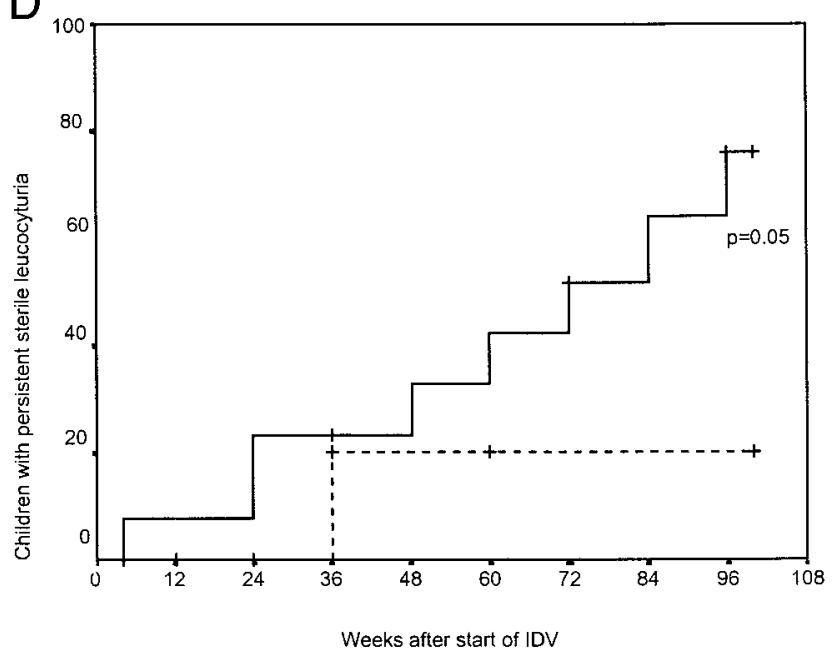

Fig 1. A, Cumulative incidence of persistent sterile leukocyturia. B, Cumulative incidence of persistent sterile leukocyturia in children $<5.6$ years (dotted line) and in children $>5.6$ years. C, Cumulative incidence of children with creatinine increase $\geq 50 \%$ above age- and sex-specific normal values. D, Cumulative incidence of persistent sterile leukocyturia in children with AUC of indinavir $\leq 19$ (dotted line) or $>19 \mathrm{mg} / \mathrm{L}^{*} \mathrm{~h}$. E, Cumulative incidence of persistent sterile leukocyturia in children with $\mathrm{C}_{\max } \leq 12$ (dotted line) or $>12 \mathrm{mg} / \mathrm{L}$. 


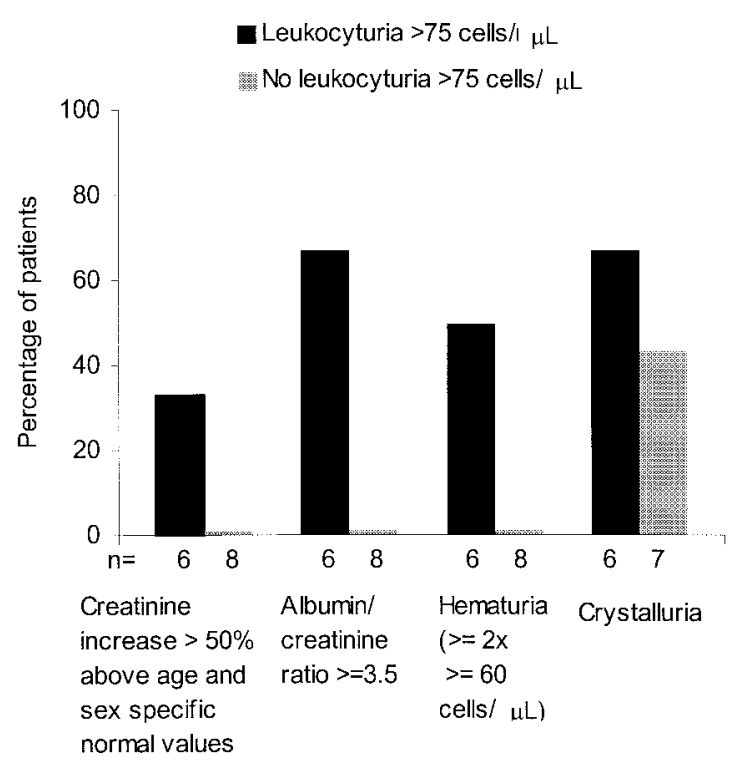

Fig 2. Urinary abnormalities associated with leukocyturia (crosssectional week 12) in 15 children included in cohort B.

Symptoms of Nephrotoxicity After Discontinuation of Indinavir Because of Nephrotoxicity

In 4 of 15 children, indinavir was discontinued because of nephrotoxic symptoms $(n=2)$ or nephrolithiasis on renal ultrasound $(n=2)$. In these children, serum creatinine $(\mu \mathrm{mol} / \mathrm{L})$ levels decreased from a median (IQR) of $54(49-75)$ at the last observation during the use of indinavir to $39(28-42) 12$ weeks after discontinuation of indinavir $(P=.07)$. The albumin/creatinine ratio decreased from 16 (9$44)$ to $0.7(0.4-2.1) \mathrm{g} / \mathrm{mmol}(P=.07)$. Leukocyturia disappeared within 3 months after the discontinuation of indinavir. Figure 3 shows the serum creatinine levels and the albumin/creatinine ratios of the 4 children that discontinued indinavir because of nephrotoxicity. Urine albumin/creatinine ratio in- creases preceded serum creatinine increases and may therefore may be an early marker of renal impairment.

In 3 other children that discontinued indinavir for other reasons (virologic failure, $n=2$, and because of the poor taste of indinavir, $n=1$ ) serum creatinine levels did not decrease, whereas the albumin/creatinine ratio showed a decrease from $3.94(0.51-11.2)$ to $0 \mathrm{~g} / \mathrm{mmol}(P=.10)$.

\section{DISCUSSION}

We here present the first study to our knowledge to monitor nephrotoxicity in HIV-1-infected children with a prolonged treatment with indinavir. We hypothesized that indinavir-related nephrotoxicity might occur more frequently in children than in adults because of the higher risk for cellular damage to the still developing renal system.

In our study, a cumulative incidence of persistent sterile leukocyturia ( $\geq 2 \times \geq 75$ cells $/ \mu \mathrm{L}$ ) of $53 \%$ was observed after 96 weeks. This persistent sterile leukocyturia was frequently accompanied by a mild increase of the urine albumin/creatinine ratio and microscopic hematuria. The cumulative incidence of an increase in serum creatinine levels $>50 \%$ above normal was 35\% after 96 weeks. Children with persistent sterile leukocyturia more frequently had an increase of serum creatinine levels of $>50 \%$ above normal $(P=.02)$. This suggests that persistent sterile leukocyturia is an early indication for the development of renal damage.

Recently, Gagnon et $\mathrm{al}^{21}$ found a significant reduction in the renal function of 3 adults with recurrent severe leukocyturia. Our data confirm the observations in adults of Gagnon et al, that reduction of renal function is associated with recurrent severe leukocyturia, but not with isolated hematuria or crystalluria. Renal damage resulting in leukocyturia and an increased creatinine may be a result of irritation of the
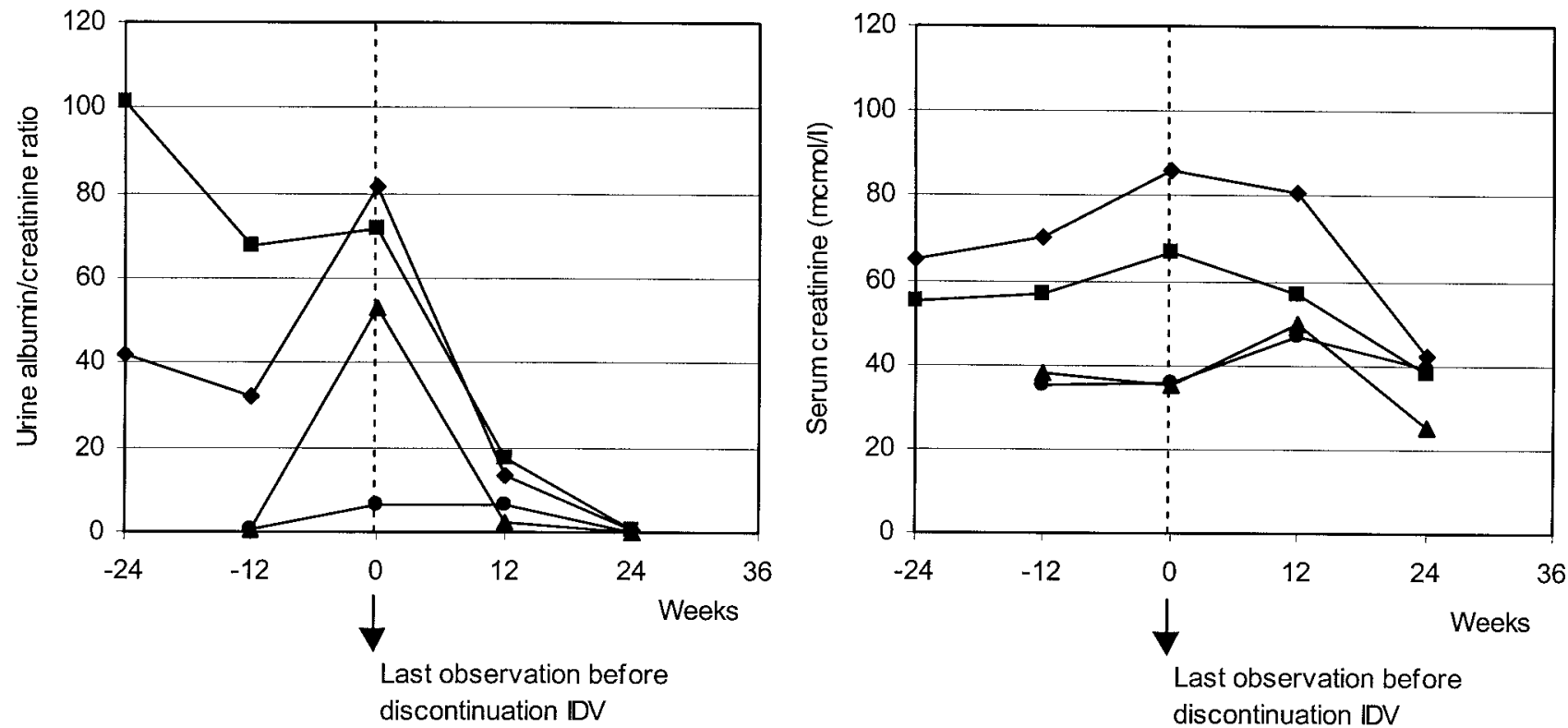

Fig 3. Urine albumin/creatinine ratio ( $\mathrm{g} / \mathrm{mmol})$ and creatinine levels $(\mu \mathrm{mol} / \mathrm{L})$ during the use of indinavir and after discontinuation of indinavir in 4 children. 
tubular epithelium. This is supported by the pathologic finding of tubulointerstitial nephritis in patients on therapy with indinavir. ${ }^{4,24,25}$

The prevalence of persistent leukocyturia in adults screened on the same nephrotoxicity monitoring program was $22 \%$ (J. P. Dieleman, personal communication, September 10, 2001), which is substantially lower than we observed in children. One might hypothesize that indinavir crystals more easily congest in the small tubuli of young children which may lead to a higher incidence of nephrolithiasis. The more frequent presence of persistent sterile leukocyturia in younger children confirms this observation. However, nephrolithiasis was only diagnosed by renal ultrasound in two asymptomatic children with persistent sterile leukocyturia. ${ }^{26}$ Renal ultrasounds of the other children with persistent leukocyturia showed no nephrolithiasis. Because it is well documented that the occurrence of indinavir nephrolithiasis increases with a poor hydration status and high environmental temperatures, ${ }^{27}$ the Dutch climate with relatively moderate temperatures may contribute to a lower incidence of nephrolithiasis in our patients. Persistent leukocyturia might have been prevented by an increased fluid intake. Because it is more difficult to achieve a large fluid intake in young children, a relatively small fluid intake in younger children may be the cause of the more frequent occurrence of persistent sterile leukocyturia in children younger than 5.6 years (cumulative incidence after 96 weeks: $78 \%$ ).

We did not observe an association between indinavir crystalluria and leukocyturia. Because indinavir crystals can develop in the urine canister, ${ }^{28}$ it is possible that crystalluria reflects the time lapse between urine collection and urinalysis.

We observed a higher cumulative incidence of persistent leukocyturia in children with an $\mathrm{AUC}_{0-8}$ of indinavir of $>19\left(\mathrm{mg} / \mathrm{L}^{*} \mathrm{~h}\right)$ and in children with a peak level of indinavir higher than $12(\mathrm{mg} / \mathrm{L})$. This is in accordance with previous publications on the relation between levels of indinavir and urologic complications in adults. An AUC of indinavir $<20$ (mg/ $\left.\mathrm{L}^{*} \mathrm{~h}\right)$ is associated with virologic failure. ${ }^{17}$ This observation complicates the treatment of HIV-1-infected children with indinavir: to achieve optimal virologic suppression, an AUC higher than 20 (mg/ $L^{*} h$ ) is required, but to avoid persistent leukocyturia, an AUC $<19\left(\mathrm{mg} / \mathrm{L}^{*} \mathrm{~h}\right)$ is needed.

These observations suggest that indinavir may be less useful in the treatment of HIV-1-infected children. However, indinavir is a very potent protease inhibitor which in combination with nucleoside analogues gives an excellent long-term clinical, virologic and immunologic response in adults and in children. ${ }^{15,29,30}$ We therefore propose to monitor nephrotoxicity very closely in children treated with indinavir and change therapy only in the case of overt signs of renal impairment. In this respect, it is reassuring that the signs of renal impairment are reversible after discontinuation of indinavir. Serum creatinine levels decreased in the 4 children with signs of nephrotoxicity who discontinued indinavir. The urine albumin/creatinine ratio returned to zero in all patients. It still remains unclear whether renal impairment is reversible in all stages of damage or that a chronic renal insufficiency will develop above a critical level of cellular damage.

\section{CONCLUSION}

Prolonged therapy with indinavir is associated with a high risk for persistent sterile leukocyturia in children especially in those younger than 5.6 years. The presence of sterile leukocyturia is associated with a significant increase in serum creatinine levels. A high AUC ( $\left.>19 \mathrm{mg} / \mathrm{L}^{*} \mathrm{~h}\right)$ and high peak levels $(>12 \mathrm{mg} / \mathrm{L})$ of indinavir are associated with the occurrence of leukocyturia. Therapeutic drug monitoring of indinavir serum levels is therefore essential to estimate the risk of nephrotoxicity. Children with risk factors for the development of nephrotoxicity, such as an age $<5.6$ years, AUC of indinavir $>19$ $\mathrm{mg} / \mathrm{L}^{*} \mathrm{~h}$, and $\mathrm{C}_{\max }>12 \mathrm{mg} / \mathrm{L}$, should be monitored routinely by means of urinalysis and analysis of serum creatinine levels.

\section{ACKNOWLEDGMENTS}

We thank Sibyl Geelen, Tom Wolfs, Henriette Scherpbier, Corry Weemaes, Jeroen van Kampen, Steef van der Valk, Lotte Sahne, and John Visser for their help with the collection of specimen and Anneke van Duuren for the data management support. We are grateful to Wim Hop for his help with the statistical analyses.

\section{REFERENCES}

1. Balani SK, Arison BH, Mathai L, et al. Metabolites of L-735, 524, a potent HIV-1 protease inhibitor, in human urine. Drug Metab Dispos. 1995;23: $266-270$

2. Kopp JB, Miller KD, Mican JA, et al. Crystalluria and urinary tract abnormalities associated with indinavir [see comments]. Ann Intern Med. 1997;127:119-125

3. Tashima KT, Horowitz JD, Rosen S. Indinavir nephropathy. N Engl J Med. 1997;336:138-140

4. Marroni M, Gaburri M, Mecozzi F, Baldelli F. Acute interstitial nephritis secondary to the administration of indinavir. Ann Pharmacother. 1998; 32:843-844

5. Martinez F, Mommeja-Marin H, Estepa-Maurice L, et al. Indinavir crystal deposits associated with tubulointerstitial nephropathy. Nephrol Dial Transplant. 1998;13:750-753

6. Perazella MA, Kashgarian M, Cooney E. Indinavir nephropathy in an AIDS patient with renal insufficiency and pyuria. Clin Nephrol. 1998;50: 194-196

7. Sarcletti M, Zangerle R. Persistent flank pain, low-grade fever, and malaise in a woman treated with indinavir. AIDS Patient Care STDS. 1999;13:81-87

8. Merck and Co. Indinavir Sulfate. West Point, PA: Merck and Co; March 1996

9. Saltel E, Angel JB, Futter NG, et al. Increased prevalence and analysis of risk factors for indinavir nephrolithiasis. J Urol. 2000;164:1895-1897

10. Wintergerst U, Hoffmann F, Solder B, et al. Comparison of two antiretroviral triple combinations including the protease inhibitor indinavir in children infected with human immunodeficiency virus. Pediatr Infect Dis J. 1998;17:495-499

11. Monpoux F, Sirvent N, Cottalorda J, Mariani R, Lefbvre JC. Stavudine, lamivudine and indinavir in children with advanced HIV-1 infection: preliminary experience [letter]. AIDS. 1997;1112:1523-5

12. Mueller B, Sleasman J, Nelson R, et al. A phase I/II study of the protease inhibitor indinavir in children with HIV infection. Pediatrics. 1998;102: 100-109

13. Gatti G, Vigano A, Sala N, et al. Indinavir pharmacokinetics and pharmacodynamics in children with human immunodeficiency virus infection. Antimicrob Agents Chemother. 2000;44:752-755

14. Melvin AJ, Mohan KM, Arcuino LA, et al. Clinical, virologic and immunologic responses of children with advanced human immunodeficiency virus type 1 disease treated with protease inhibitors. Pediatr Infect Dis J. 1997;16:968-974

15. van Rossum AMC, Niesters HG, Geelen SP, et al. Clinical and virologic 
response to combination treatment with indinavir, zidovudine, and lamivudine in children with human immunodeficiency virus-1 infection: a multicenter study in The Netherlands. J Pediatr. 2000;136: $780-788$

16. Dieleman JP, Gyssens IC, van der Ende ME, de Marie S, Burger DM. Urological complaints in relation to indinavir plasma concentrations in HIV-infected patients. AIDS. 1999;13:473-478

17. Burger DM, van Rossum AMC, Hugen PW, et al. Pharmacokinetics of the protease inhibitor indinavir in human immunodeficiency virus type 1-infected children. Antimicrob Agents Chemother. 2001;45:701-705

18. Burger DM, Hoetelmans RMW, Hugen PWH, et al. Low plasma concentrations of indinavir are related to virological treatment failure in HIV-1-infected patients on indinavir-containing triple therapy. Antiviral Ther. 1998;3:215-220

19. Harris M, Durakovic C, Rae S, et al. A pilot study of nevirapine, indinavir, and lamivudine among patients with advanced human immunodeficiency virus disease who have had failure of combination nucleoside therapy. J Infect Dis. 1998;177:1514-520

20. Stein DS, Fish DG, Bilello JA, Preston SL, Martineau GL, Drusano GL. A 24-week open-label phase I/II evaluation of the HIV protease inhibitor MK-639 (indinavir). AIDS. 1996;10:485-492

21. Gagnon RF, Tecimer SN, Watters AK, Hatzakis GE, Tsoukas CM. The natural history of leukocyturia associated with indinavir treatment in HIV + individuals. Am J Nephrol. 2000;206:448-454

22. John H, Muller NJ, Opravil M, Hauri D. Indinavir urinary stones as origin of upper urinary tract obstruction. Urol Int. 1997;594:257-259

23. Schwartz GJ, Haycock GB, Spitzer A. Plasma creatinine and urea concentration in children: normal values for age and sex. J Pediatr. 1976; 885:828-830

24. Sarcletti M, Petter A, Zangerle R. Indinavir and interstitial nephritis. Ann Intern Med. 1998;1284:320-321

25. Jaradat M, Phillips C, Yum MN, Cushing H, Moe S. Acute tubulointerstitial nephritis attributable to indinavir therapy. Am J Kidney Dis. 2000;35:E16

26. van Rossum AMC, Dieleman JP, Fraaij PLA, et al. Indinavir-associated asymptomatic nephrolithiasis and renal cortex atrophy in two HIV-1 infected children. AIDS. 2001;15:1745-1747

27. Martinez E, Leguizamon M, Mallolas J, Miro JM, Gatell JM. Influence of environmental temperature on incidence of indinavir-related nephrolithiasis. Clin Infect Dis. 1999;292:422-425

28. Salahuddin S, Hsu YS, Buchholz NP, Dieleman JP, Gyssens IC, Kok DJ. Is indinavir crystalluria an indicator for indinavir stone formation? AIDS. 2001;15:1079-1080

29. Gulick RM, Mellors JW, Havlir D, et al. 3-year suppression of HIV viremia with indinavir, zidovudine, and lamivudine. Ann Intern Med. 2000;133:35-39

30. Vigano A, Dally L, Bricalli D, et al. Clinical and immuno-virologic characterization of the efficacy of stavudine, lamivudine, and indinavir in human immunodeficiency virus infection. J Pediatr. 1999;135:675-682 


\section{Persistent Sterile Leukocyturia Is Associated With Impaired Renal Function in Human Immunodeficiency Virus Type 1-Infected Children Treated With Indinavir}

Annemarie M. C. van Rossum, Jeanne P. Dieleman, Pieter L. A. Fraaij, Karlien Cransberg, Nico G. Hartwig, David M. Burger, Inge C. Gyssens and Ronald de Groot Pediatrics 2002;110;19.

DOI: $10.1542 /$ peds.110.2.e19

This information is current as of November 15, 2006

\begin{tabular}{|c|c|}
\hline $\begin{array}{l}\text { Updated Information } \\
\text { \& Services }\end{array}$ & $\begin{array}{l}\text { including high-resolution figures, can be found at: } \\
\text { http://www.pediatrics.org/cgi/content/full/110/2/e19 }\end{array}$ \\
\hline References & $\begin{array}{l}\text { This article cites } 20 \text { articles, } 7 \text { of which you can access for } \\
\text { at: } \\
\text { http://www.pediatrics.org/cgi/content/full/110/2/e19\#BIBI }\end{array}$ \\
\hline Citations & $\begin{array}{l}\text { This article has been cited by } 1 \text { HighWire-hosted articles: } \\
\text { http://www.pediatrics.org/cgi/content/full/110/2/e19\#other } \\
\text { s }\end{array}$ \\
\hline Subspecialty Collections & $\begin{array}{l}\text { This article, along with others on similar topics, appears in } \\
\text { following collection(s): } \\
\text { Infectious Disease \& Immunity } \\
\text { http://www.pediatrics.org/cgi/collection/infectious_disease }\end{array}$ \\
\hline Permissions \& Licensing & $\begin{array}{l}\text { Information about reproducing this article in parts (figures } \\
\text { tables) or in its entirety can be found online at: } \\
\text { http://www.pediatrics.org/misc/Permissions.shtml }\end{array}$ \\
\hline Reprints & $\begin{array}{l}\text { Information about ordering reprints can be found online: } \\
\text { http://www.pediatrics.org/misc/reprints.shtml }\end{array}$ \\
\hline
\end{tabular}

Updated Information

\& Services http://www.pediatrics.org/misc/reprints.shtml 